\title{
COMPARISON OF DESIGN OF EXPERIMENTS VIA TRADITIONAL AND TAGUCHI METHODFOR
}

\author{
M. N. ISLAM* \\ Department of Mechanical Engineering, Curtin University \\ Perth, WA 6102, Australia \\ M.N.Islam@curtin.edu.au \\ A. PRAMANIK \\ Department of Mechanical Engineering, Curtin University \\ Perth, WA 6102, Australia \\ alokesh.pramanik@curtin.edu.au \\ Received (Day Month Year) \\ Revised (Day Month Year)
}

\begin{abstract}
This paper presents a case study on comparison of Design of Experiments (DOE) via traditional and Taguchi methods in terms of efficiency. First, a three-level, four-parameter, full factorial DOE was conducted for finding the effects of machining parameters on the surface roughness (arithmetic average) of parts produced by turning operation. The results were analyzed applying average response, Taguchi's S/N ratio, and Pareto ANOVA. Subsequently, the same data was analyzed applying Taguchi's L9 orthogonal array. The comparison of two results revealed that despite an $88.9 \%$ savings of experimental runs with the Taguchi method, both methods produced similar results.
\end{abstract}

Keywords: Design of experiments; Taguchi method; signal-to-noise ratio; Pareto ANOVA.

\section{Introduction}

Design of experiments (DOE) is a powerful tool for experimentation widely used by researchers and engineers in all fields of study for finding the effects of input parameters on output parameters. It is the process of planning experiments for appropriate data collection through the least number of experiments. Essentially, DEO is the scientific management of information acquisition by experiment. ${ }^{1}$

DOE methodology was first proposed by R. A. Fisher in England in the 1920's. ${ }^{2}$ His original work dealt with agricultural applications of statistical methods. He sought to find out how much rain, water, fertilizer, sunshine, etc. are needed to produce the best crop and pioneered the DOE methodology also known as factorial DOE. Factorial DOE can be full or partial. A full factorial DOE considers all possible combinations for a given set of factors and their levels. In general, full factorial DOE requires $n^{k}$ number of experimental

* Corresponding author. 
runs, where $n$ is the number of factor levels and $k$ is the number of factors considered. The main advantage of this method is that it takes into account all the main and interaction effects, providing a full picture. However, the method requires a large number of experimental runs which are cumbersome, time consuming and expensive. The alternative is fractional factorial DOE in which only a small set of experimental runs are selected from a full factorial design. As a result, the interaction effects are often disregarded. While the fractional factorial method is well known, it is problematic as there are no guidelines for its application and subsequent analysis. ${ }^{3}$

Taguchi formalized the fractional factorial DOE method and published a library of orthogonal arrays, which reduced the number of required experiments significantly. The method is simple and easy to apply. Orthogonality of the DOE permits the separation of the individual effects of each of several variables. Details of Taguchi's orthogonal arrays can be found in the literature. ${ }^{4}$ Taguchi's orthogonal array is represented in a symbolic format as $L_{a}\left(b^{c}\right)$, where the letter ' $L$ ' indicates that the experimental designs are associated with Latin square designs, $a$ is the number of runs, $b$ is the number of levels considered, and $c$ is the number of columns (number of factors). ${ }^{5}$ Thus, $L_{9}\left(3^{4}\right)$ represents that a total of 9 experimental runs will be conducted for a three-level, four-parameter experiment. A full factorial DOE conducted by the traditional method for the same study will need $3^{4}=81$ experiments. Hence, for an industrial application, the Taguchi method provides a significant savings of experimental runs.

Another difference between DOE via traditional and the Taguchi method is how the collected data are analyzed. In the traditional analysis, the average values of the response data are used, whereas the Taguchi method utilizes both average and variation of data. Therefore, the Taguchi method is expected to produce better results because it guarantees the highest quality with minimum variance. Taguchi proposed the $\mathrm{S} / \mathrm{N}$ ratio as a quantitative analysis tool for optimizing the outcome of a process. Taguchi classifies quality characteristics into three categories: (i) the smaller the better, (ii) the larger the better, and (iii) the nominal the better. The formula for calculating the $\mathrm{S} / \mathrm{N}$ ratio depends on the type of quality characteristics investigated. For example, Equation 1 calculates the $\mathrm{S} / \mathrm{N}$ ratio of a quality characteristic in which the adage "the smaller the better" holds true. ${ }^{6}$

$$
S / N=-10 \log \frac{1}{n}\left(\sum_{i=1}^{n} y_{i}^{2}\right)
$$

where $n$ is the number of observations and $y$ is the observed data.

It is worth pointing out the main emphasis of the Taguchi method is on robust design, i.e. making a product's quality of performance insensitive to variations in manufacture, in-service wear, and in-service environmental variations. It is a tool for quality improvement and cost reduction rather than determining the casual relationships of how things happen. Therefore, the major difference between the traditional DOE and the 
Taguchi method is at a philosophical level. The Taguchi approach is more engineeringoriented than science-oriented. ${ }^{1}$

Design of Experiments via both traditional ${ }^{7-10}$ and Taguchi methods ${ }^{11-14}$ are widely used in manufacturing. However, there are ongoing debates ${ }^{15,16}$ on the statistical techniques used by Taguchi to implement his robust design philosophy. The practitioners of the Taguchi method clamor for its simplicity and effectiveness in solving real engineering problems. It is worth testing these claims. Therefore, in this paper, we present a case study that compares the performance of the traditional as well as Taguchi DEO for an engineering application. This will help professionals optimize relevant engineering processes at a low cost and in less time.

\section{Research Strategy}

To achieve the above stated goal, we have selected a typical process optimization example from manufacturing. A full factorial DOE was planned to determine the influences of four major cutting parameters on a key machinability characteristic - the surface roughness (arithmetic average). The selected input parameters are cutting speed, feed rate, depth of cut and amount of cutting fluid. Each input parameter has three levels as shown in Table 1.

Table 1. Input parameters and their level.

\begin{tabular}{lccccc}
\hline Input Parameters & Unit & Symbol & \multicolumn{3}{c}{ Levels } \\
& & & Level 0 & Level 1 & Level 2 \\
\hline Cutting speed & $\mathrm{m} / \mathrm{min}$ & $\mathrm{A}$ & 64 & 128 & 256 \\
Feed arte & $\mathrm{mm} / \mathrm{rev}$ & $\mathrm{B}$ & 0.11 & 0.22 & 0.33 \\
Depth of cut & $\mathrm{mm}$ & $\mathrm{C}$ & 0.5 & 1.0 & 1.5 \\
Amount of cutting fluid & lit/min & $\mathrm{D}$ & 0 & 1.3 & 2.6 \\
\hline
\end{tabular}

The results were analyzed applying average response, Taguchi's $\mathrm{S} / \mathrm{N}$ ratio, and Pareto ANOVA. Pareto ANOVA is an excellent tool for determining the contribution of each input parameter and its interactions with the output parameters. It is a simplified ANOVA analysis method that does not require an ANOVA table and does not use F-tests. Consequently, it does not require detailed knowledge about the ANOVA method. A detailed treatment of Pareto ANOVA in the literature. ${ }^{1}$

Taguchi's L9 orthogonal array is a partial DEO of a full factorial run. A set of experimental runs, as per Taguchi's orthogonal array, was selected from the full factorial DEO. Two results were compared in terms of their efficiency.

\section{Experimental Work}

This study was performed on a turning of mild steel AISI 1030 which is readily available and widely used in the industry. A total of 81 experimental runs were conducted; they were carried out on 9 parts, each of which was divided into 9 segments. Each segment 
was turned with the cutting conditions determined by traditional DOE. The positions of the segments were allocated randomly. The nominal size of each part was $270 \mathrm{~mm}$ length and $40 \mathrm{~mm}$ diameter. The experiment was carried out on a Harrison conventional lathe with $330 \mathrm{~mm}$ swing. For holding the workpiece, a three-jaw chuck supported at dead center was employed. Square-shaped inserts with enriched cobalt coating (CVD TiNTiCN-Al2O3-TiN) manufactured by Stellram, USA, were used as cutting tools. A new cutting tip was used for machining each part to avoid any tool wear effect. Where applicable, Castrol Clearedge EP690, a semi-synthetic soluble cutting fluid, was applied. The surface roughness parameter arithmetic average $(\mathrm{Ra})$ for each turned surface was measured by a surface-measuring instrument, the Surftest SJ-201P, manufactured by Mitutoyo, Japan.

\section{Results and Discussion}

The experimental results of traditional DEO are summarized in Table 2. Both average response and $\mathrm{S} / \mathrm{N}$ ratio are included in Table 2. The experimental data then are analyzed by Pareto ANOVA, S/N ratio, and average response.

The Pareto ANOVA using data from traditional DEO is illustrated in Table 3 . It demonstrates that cutting speed (A) has the most significant effect on surface roughness with a contribution ratio ( $\mathrm{P} \cong 48 \%$ ), followed by feed rate $(\mathrm{B})(\mathrm{P} \cong 27 \%$ ). Contributions of depth of cut (C) and amount of cutting fluid (D) are negligible. The interaction between cutting speed and feed rate $(A \times B)$ also played a role $(P \cong 12 \%)$. It is worth noting that the total contribution of the main effects is about $74 \%$, compared to the $26 \%$ total contribution of the interaction effects, thus making it moderately difficult to optimize the surface roughness by selection of input parameters.

The response graphs of the $\mathrm{S} / \mathrm{N}$ ratio using data from traditional DOE are presented in Fig. 1. As the slopes represent the strength of contribution, the response graphs confirm the findings of the Pareto ANOVA given in Table 3, i.e. parameters A and $\mathrm{B}$ have significant effects whereas parameters $\mathrm{C}$ and $\mathrm{D}$ have negligible effects on surface roughness. Fig. 1 also shows that the best combination of input variables for minimizing surface roughness is A2B0C2D2; i.e. high level cutting speed (256 m/min), low level of feed rate $(0.11 \mathrm{~mm} / \mathrm{rev})$, high level of depth of cut $(1.5 \mathrm{~mm})$, and high level of amount of cutting fluid (2.6 lit/min).

Taguchi's L9 orthogonal array is a partial DEO of full factorial run presented in Table 2. The experimental results using data from the L9 orthogonal array are summarized in Table 4. Both average response $\mathrm{S} / \mathrm{N}$ ratios are included in Table 4. The experimental data are then analyzed by Pareto ANOVA, $\mathrm{S} / \mathrm{N}$ ratio, and average response.

The response graphs of $\mathrm{S} / \mathrm{N}$ ratio using data from the L9 orthogonal array are presented in Fig. 2. From this figure, it can be seen that the best combination of input variables for minimizing surface roughness is A2B0C2D1; i.e. high level cutting speed $(256 \mathrm{~m} / \mathrm{min})$, low level of feed rate $(0.11 \mathrm{~mm} / \mathrm{rev})$, high level of depth of cut $(1.5 \mathrm{~mm})$, and medium level of amount of cutting fluid (1.3 lit/min). 
Table 2. Experimental results of traditional DOE.

\begin{tabular}{|c|c|c|c|c|c|c|c|c|c|c|c|c|c|}
\hline Trial No & A & $\mathrm{B}$ & C & $\mathrm{D}$ & Average & S/N Ratio & Trial No & A & B & $\mathrm{C}$ & $\mathrm{D}$ & Average & S/N Ratio \\
\hline 1 & 0 & 0 & 0 & 0 & 4.024 & -12.098 & 42 & 1 & 1 & 1 & 2 & 1.651 & -4.357 \\
\hline 2 & 0 & 0 & 0 & 1 & 5.102 & -14.160 & 43 & 1 & 1 & 2 & 0 & 1.914 & -5.640 \\
\hline 3 & 0 & 0 & 0 & 2 & 4.860 & -13.784 & 44 & 1 & 1 & 2 & 1 & 1.943 & -5.776 \\
\hline 4 & 0 & 0 & 1 & 0 & 5.605 & -14.972 & 45 & 1 & 1 & 2 & 2 & 1.624 & -4.211 \\
\hline 5 & 0 & 0 & 1 & 1 & 4.507 & -13.107 & 46 & 1 & 2 & 0 & 0 & 3.725 & -11.422 \\
\hline 6 & 0 & 0 & 1 & 2 & 5.153 & -14.285 & 47 & 1 & 2 & 0 & 1 & 3.806 & -11.621 \\
\hline 7 & 0 & 0 & 2 & 0 & 4.264 & -12.625 & 48 & 1 & 2 & 0 & 2 & 2.984 & -10.363 \\
\hline 8 & 0 & 0 & 2 & 1 & 4.374 & -12.824 & 49 & 1 & 2 & 1 & 0 & 4.120 & -12.298 \\
\hline 9 & 0 & 0 & 2 & 2 & 3.914 & -11.860 & 50 & 1 & 2 & 1 & 1 & 3.891 & -11.802 \\
\hline 10 & 0 & 1 & 0 & 0 & 4.933 & -13.909 & 51 & 1 & 2 & 1 & 2 & 4.081 & -12.216 \\
\hline 11 & 0 & 1 & 0 & 1 & 6.228 & -15.916 & 52 & 1 & 2 & 2 & 0 & 3.987 & -12.013 \\
\hline 12 & 0 & 1 & 0 & 2 & 5.390 & -14.648 & 53 & 1 & 2 & 2 & 1 & 4.058 & -12.167 \\
\hline 13 & 0 & 1 & 1 & 0 & 4.003 & -12.048 & 54 & 1 & 2 & 2 & 2 & 3.487 & -10.850 \\
\hline 14 & 0 & 1 & 1 & 1 & 4.499 & -13.086 & 55 & 2 & 0 & 0 & 0 & 1.313 & -2.391 \\
\hline 15 & 0 & 1 & 1 & 2 & 4.667 & -13.424 & 56 & 2 & 0 & 0 & 1 & 0.879 & 1.038 \\
\hline 16 & 0 & 1 & 2 & 0 & 3.311 & -10.401 & 57 & 2 & 0 & 0 & 2 & 0.987 & 0.071 \\
\hline 17 & 0 & 1 & 2 & 1 & 4.500 & -13.071 & 58 & 2 & 0 & 1 & 0 & 1.217 & -1.709 \\
\hline 18 & 0 & 1 & 2 & 2 & 4.410 & -12.907 & 59 & 2 & 0 & 1 & 1 & 0.987 & 0.101 \\
\hline 19 & 0 & 2 & 0 & 0 & 6.894 & -16.777 & 60 & 2 & 0 & 1 & 2 & 1.145 & -1.177 \\
\hline 20 & 0 & 2 & 0 & 1 & 6.315 & -16.009 & 61 & 2 & 0 & 2 & 0 & 1.176 & -1.413 \\
\hline 21 & 0 & 2 & 0 & 2 & 5.915 & -15.481 & 62 & 2 & 0 & 2 & 1 & 1.002 & -0.024 \\
\hline 22 & 0 & 2 & 1 & 0 & 6.045 & -15.651 & 63 & 2 & 0 & 2 & 2 & 1.148 & -1.231 \\
\hline 23 & 0 & 2 & 1 & 1 & 5.300 & -14.485 & 64 & 2 & 1 & 0 & 0 & 2.003 & -6.039 \\
\hline 24 & 0 & 2 & 1 & 2 & 4.361 & -12.799 & 65 & 2 & 1 & 0 & 1 & 1.893 & -5.543 \\
\hline 25 & 0 & 2 & 2 & 0 & 4.508 & -13.103 & 66 & 2 & 1 & 0 & 2 & 2.133 & -6.581 \\
\hline 26 & 0 & 2 & 2 & 1 & 4.755 & -13.552 & 67 & 2 & 1 & 1 & 0 & 1.955 & -5.823 \\
\hline 27 & 0 & 2 & 2 & 2 & 5.462 & -14.761 & 68 & 2 & 1 & 1 & 1 & 2.343 & -7.394 \\
\hline 28 & 1 & 0 & 0 & 0 & 2.490 & -7.939 & 69 & 2 & 1 & 1 & 2 & 1.950 & -5.808 \\
\hline 29 & 1 & 0 & 0 & 1 & 2.961 & -9.437 & 70 & 2 & 1 & 2 & 0 & 1.812 & -5.174 \\
\hline 30 & 1 & 0 & 0 & 2 & 2.744 & -8.774 & 71 & 2 & 1 & 2 & 1 & 2.301 & -7.240 \\
\hline 31 & 1 & 0 & 1 & 0 & 1.885 & -5.519 & 72 & 2 & 1 & 2 & 2 & 1.561 & -3.871 \\
\hline 32 & 1 & 0 & 1 & 1 & 2.352 & -7.448 & 73 & 2 & 2 & 0 & 0 & 3.822 & -11.645 \\
\hline 33 & 1 & 0 & 1 & 2 & 2.365 & -7.542 & 74 & 2 & 2 & 0 & 1 & 3.986 & -12.012 \\
\hline 34 & 1 & 0 & 2 & 0 & 1.500 & -3.635 & 75 & 2 & 2 & 0 & 2 & 3.181 & -10.173 \\
\hline 35 & 1 & 0 & 2 & 1 & 2.088 & -6.396 & 76 & 2 & 2 & 1 & 0 & 3.827 & -11.657 \\
\hline 36 & 1 & 0 & 2 & 2 & 1.982 & -6.010 & 77 & 2 & 2 & 1 & 1 & 3.962 & -11.959 \\
\hline 37 & 1 & 1 & 0 & 0 & 1.592 & -4.481 & 78 & 2 & 2 & 1 & 2 & 3.820 & -11.643 \\
\hline 38 & 1 & 1 & 0 & 1 & 1.498 & -3.531 & 79 & 2 & 2 & 2 & 0 & 4.288 & -12.644 \\
\hline 39 & 1 & 1 & 0 & 2 & 1.832 & -5.273 & 80 & 2 & 2 & 2 & 1 & 3.823 & -11.649 \\
\hline 40 & 1 & 1 & 1 & 0 & 2.420 & -7.675 & 81 & 2 & 2 & 2 & 2 & 3.780 & -11.550 \\
\hline 41 & 1 & 1 & 1 & 1 & 1.564 & -3.916 & & & & & & & \\
\hline
\end{tabular}




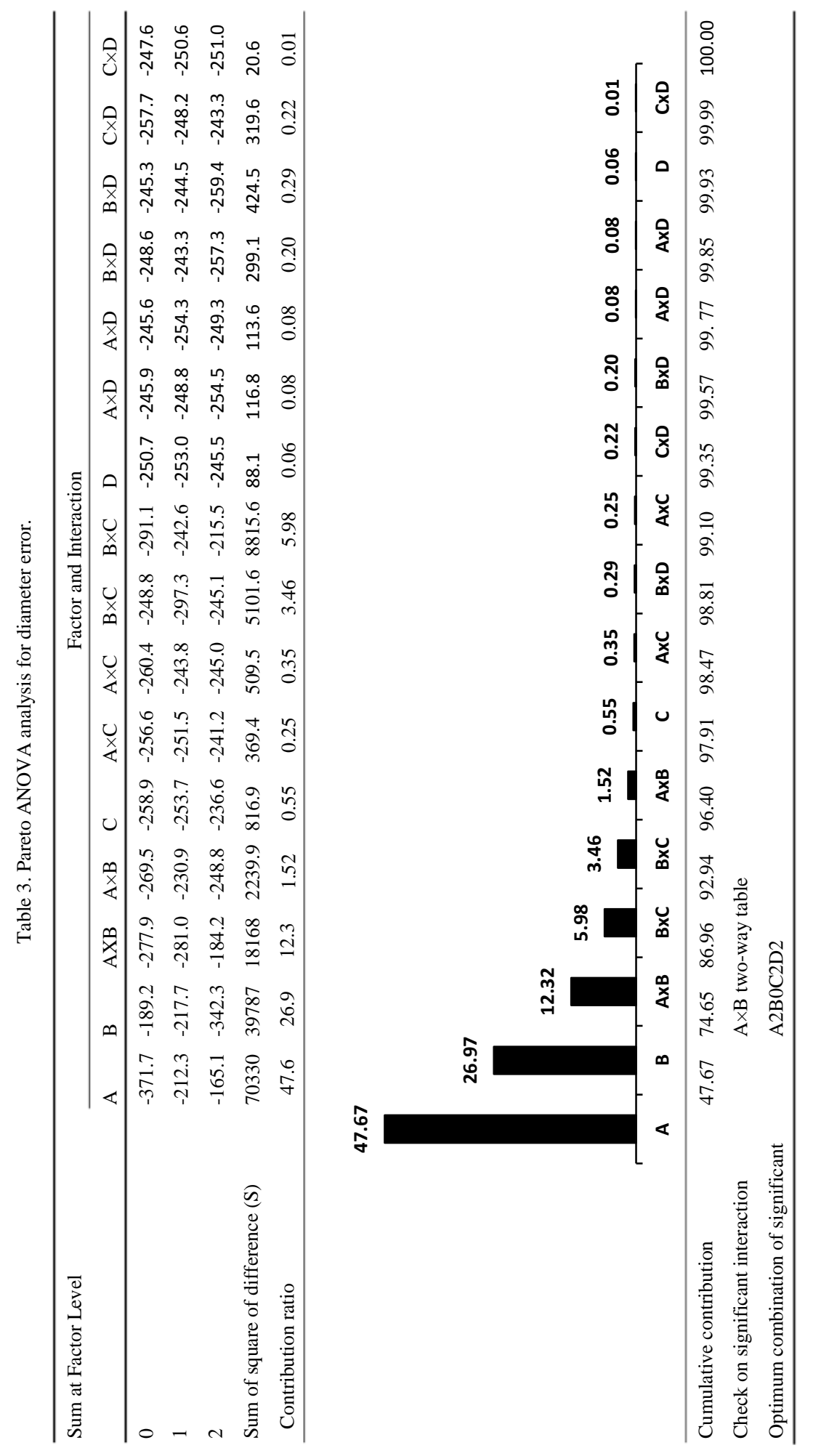


Table 4. Experimental results using L9 orthogonal array.

\begin{tabular}{cccccccccccccc}
\hline Trial No & A & B & C & D & Average & S/N Ratio & Trial No & A & B & C & D & Average & S/N Ratio \\
\hline 1 & 0 & 0 & 0 & 0 & 4.024 & -12.098 & 47 & 1 & 2 & 0 & 1 & 3.806 & -11.621 \\
14 & 0 & 1 & 1 & 1 & 4.499 & -13.086 & 62 & 2 & 0 & 2 & 1 & 1.002 & -0.024 \\
27 & 0 & 2 & 2 & 2 & 5.462 & -14.761 & 66 & 2 & 1 & 0 & 2 & 2.133 & -6.581 \\
33 & 1 & 0 & 1 & 2 & 2.365 & -7.542 & 76 & 2 & 2 & 1 & 0 & 3.827 & -11.657 \\
43 & 1 & 1 & 2 & 0 & 1.914 & -5.640 & & & & & & & \\
\hline
\end{tabular}

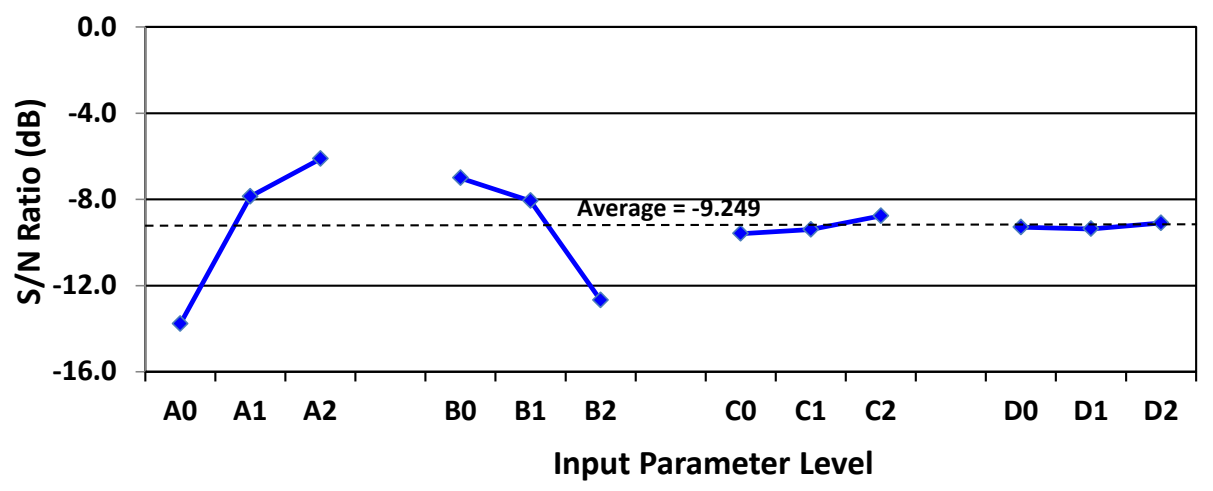

Fig. 1. Response graphs of S/N ratio using traditional DOE.

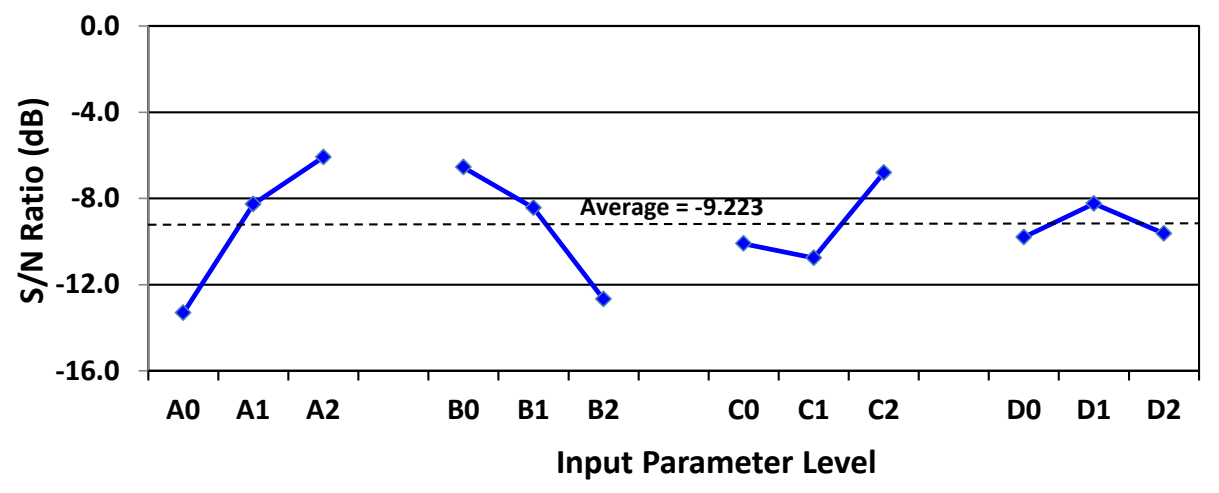

Fig. 2. Response graphs of S/N ratio using L9 orthogonal array.

Figures 1 and 2 show the effects of input parameters at different levels are very similar for both cases with some minor differences for depth of cut (C) and amount of cutting fluid (D). However, this is not a significant factor as the contributions of these two parameters on surface roughness are negligible (see Table 3). The best combination for traditional DEO is A2B0C2D2 whereas the best combination for traditional DEO is A2B0C2D1. The only difference is for parameter $D$ whose response is flat (see Fig. 1). 
A comparison of the $\mathrm{S} / \mathrm{N}$ ratios of the two methods is presented in Table 5 . This comparison shows that the absolute differences in $\mathrm{S} / \mathrm{N}$ ratios of the two methods are small for all the considered parameters and levels. The relative differences are also small for the main contributing parameters $\mathrm{A}$ and $\mathrm{B}$; however the relative differences for minor contributing parameters $\mathrm{C}$ and $\mathrm{D}$ are a bit high.

The effect of different input parameters and their levels on average response is presented in Fig. 3. It shows that the variation of surface roughness analyzed by traditional DOE and Taguchi’s L9 orthogonal array are small.

Table 5 Comparison of $\mathrm{S} / \mathrm{N}$ ratios

\begin{tabular}{|c|c|c|c|c|}
\hline \multirow[t]{2}{*}{ Parameter Level } & \multicolumn{2}{|c|}{ S/N Ratio } & \multirow{2}{*}{$\begin{array}{c}\text { Absolute } \\
\text { Difference }\end{array}$} & \multirow{2}{*}{$\begin{array}{c}\text { Relative } \\
\text { Difference (\%) }\end{array}$} \\
\hline & DOE & L9 & & \\
\hline A0 & -13.768 & -13.315 & 0.453 & -3.291 \\
\hline A1 & -7.863 & -8.268 & -0.404 & 5.140 \\
\hline A2 & -6.116 & -6.087 & 0.029 & -0.475 \\
\hline B0 & -7.006 & -6.555 & 0.451 & -6.435 \\
\hline B1 & -8.065 & -8.436 & -0.371 & 4.604 \\
\hline B2 & -12.678 & -12.679 & -0.002 & 0.012 \\
\hline $\mathrm{C} 0$ & -9.589 & -10.100 & -0.511 & 5.332 \\
\hline $\mathrm{C} 1$ & -9.396 & -10.762 & -1.365 & 14.532 \\
\hline $\mathrm{C} 2$ & -8.763 & -6.808 & 1.955 & -22.306 \\
\hline D0 & -9.285 & -9.798 & -0.513 & 5.526 \\
\hline D1 & -9.370 & -8.244 & 1.126 & -12.020 \\
\hline $\mathrm{D} 2$ & -9.093 & -9.628 & -0.535 & 5.887 \\
\hline Overall Average & -9.249 & -9.223 & 0.026 & -0.281 \\
\hline
\end{tabular}

Table 6. Comparison of average responses.

\begin{tabular}{|c|c|c|c|c|}
\hline \multirow[t]{2}{*}{ Parameter Level } & \multicolumn{2}{|c|}{ Average Response } & \multirow{2}{*}{$\begin{array}{c}\text { Absolute } \\
\text { Difference }\end{array}$} & \multirow{2}{*}{$\begin{array}{c}\text { Relative } \\
\text { Difference (\%) }\end{array}$} \\
\hline & DOE & L9 & & \\
\hline $\mathrm{A} 0$ & -0.275 & -5.570 & -0.275 & -5.570 \\
\hline A1 & 0.082 & 3.138 & 0.082 & 3.138 \\
\hline A2 & 0.014 & 0.607 & 0.014 & 0.607 \\
\hline B0 & -0.204 & -7.646 & -0.204 & -7.646 \\
\hline B1 & 0.037 & 1.316 & 0.037 & 1.316 \\
\hline B2 & -0.012 & -0.274 & -0.012 & -0.274 \\
\hline $\mathrm{CO}$ & -0.142 & -4.100 & -0.142 & -4.100 \\
\hline $\mathrm{C} 1$ & 0.243 & 7.317 & 0.243 & 7.317 \\
\hline $\mathrm{C} 2$ & -0.280 & -9.112 & -0.280 & -9.112 \\
\hline D0 & -0.028 & -0.853 & -0.028 & -0.853 \\
\hline D1 & -0.265 & -7.871 & -0.265 & -7.871 \\
\hline D2 & 0.644 & 24.066 & 0.644 & 24.066 \\
\hline Overall Average & 3.241 & 3.226 & -0.016 & -0.478 \\
\hline
\end{tabular}


A comparison of the average responses of the two methods is presented in Table 6 This comparison shows that the absolute differences in $\mathrm{S} / \mathrm{N}$ ratios of the two methods are small for all the considered parameters and levels. The relative differences are also small for the main contributing parameters $\mathrm{A}$ and $\mathrm{B}$, whereas the relative differences are a bit high for minor contributing parameters $\mathrm{C}$ and $\mathrm{D}$.

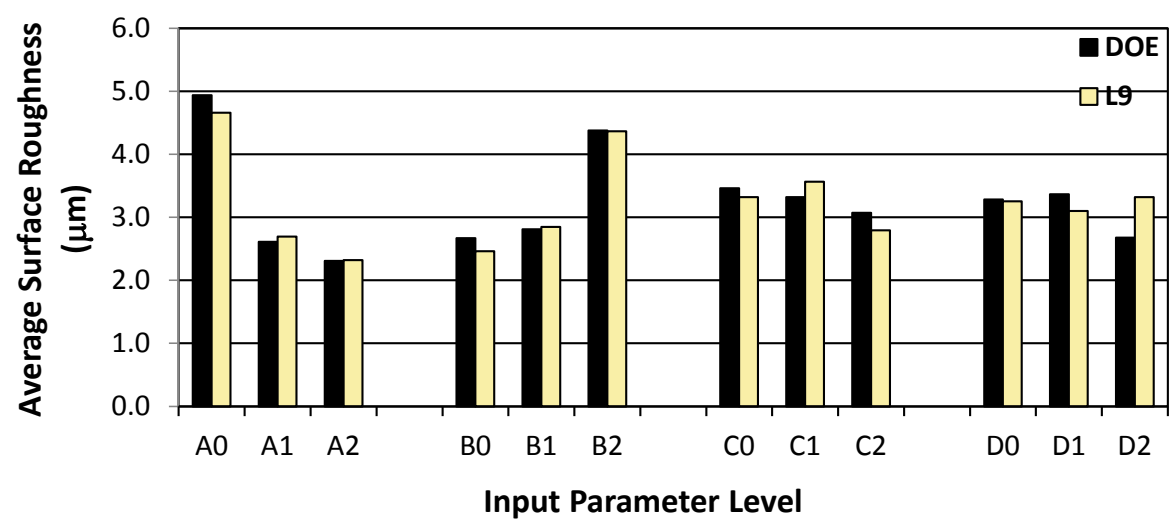

Fig. 3. Comparison of average responses.

\section{Concluding Remarks}

Design of Experiments via the Taguchi and traditional methods have been compared. From the results obtained, the following can be concluded:

- Despite an $88.9 \%$ savings of experimental runs with the Taguchi method, both methods produced similar results.

- The best combination of input variables from traditional DEO $\left(\mathrm{A}_{2} \mathrm{~B}_{0} \mathrm{C}_{2} \mathrm{D}_{2}\right)$ and Taguchi's orthogonal array $\left(\mathrm{A}_{2} \mathrm{~B}_{0} \mathrm{C}_{2} \mathrm{D}_{1}\right)$ produced similar results; the only difference was for parameter $\mathrm{D}$ whose contribution is negligible ( $\mathrm{P} \cong 0.08 \%$ ).

- The Taguchi method is easy to implement and no advanced knowledge of statistics is required.

- The Taguchi method is an excellent tool for optimising an intermediate number of variables (3 to 50) where only a few variables contribute significantly and interaction effects are relatively low.

\section{References}

1. Park, S.H. (1996). Robust Design and Analysis for Quality Engineering. Chapman \& Hall, London.

2. Montgomery, D.C. (2008). Design and Analysis of Experiments. John Wiley \& Sons.

3. Introduction to Taguchi Method, http://www.ecs.umass.edu/mie/labs/mda/fea /sankar/chap2.html, accessed 10 September 2014.

4. Taguchi, G. (1987.) System of Experimental Design: Engineering Methods to Optimize Quality and Minimize Cost. Vol. 2, UNIPUB/Kraus Int. Pub., White Plains, NY. 
5. Taguchi, S. (2013). Roust Engineering (Taguchi Methods). Workshop Materials, April 22-23, 2013, UTM, Kuala Lumpur.

6. Ross, P.J. (1988). Taguchi Techniques for Quality Engineering. McGraw-Hill, New York.

7. Fountas, N., Vaxevanidis, N., Stergiou, C., \& Benhadj-Djilali, R. (2014). Evaluation of 3-and 5-axis sculptured surface machining in CAM environment through design of experiments. International Journal of Computer Integrated Manufacturing, (ahead-of-print): 1-19.

8. Watkins, D., Bergman, A., \& Horton, R. (1994). Optimization of tool life on the shop floor using design of experiments. Quality Engineering, 6(4): 609-620.

9. Lin, T., \& Chananda, B. (2003). Quality improvement of an injection-molded product using design of experiments: a case study. Quality Engineering, 16(1): 99-104.

10. Fountas, N. A., Vaxevanidis, N. M., Stergiou, C. I., \& Benhadj-Djilali, R. (2014a). Optimum CNC free-form surface machining through design of experiments in CAM software. In Modern Mechanical Engineering (pp. 241-283). Springer Berlin Heidelberg.

11. Kim, S. J., Kim, K. S., \& Jang, H. (2003). Optimization of manufacturing parameters for a brake lining using Taguchi method. Journal of Materials Processing Technology, 136(1): 202208.

12. Tong, L. I., Su, C. T., \& Wang, C. H. (1997). The optimization of multi-response problems in the Taguchi method. International Journal of Quality \& Reliability Management, 14(4): 367380.

13. Islam, M. N. (2013). Effect of additional factors on dimensional accuracy and surface finish of turned parts. Machining Science and Technology, 17(1): 145-162.

14. Islam, M. N., Anggono, J. et al. (2013a). Effect of cooling methods on dimensional accuracy and surface finish of a turned titanium part. The International Journal of Advanced Manufacturing Technology, 69(9-12): 2711-2722.

15. Nair, Vijayan N., et al. (1992). Taguchi's parameter design: a panel discussion. Technometrics 34(2): 127-161.

16. Taguchi DOE vs Traditional DOE, iSix Sigma, http://www.isixsigma.com/topic/ taguchi-doevs-traditional-doe/, accessed 10 September 2014. 